\title{
RELATIONSHIP BETWEEN ORAL HEALTH-RELATED QUALITY OF LIFE AND SALIVARY CORTISOL LEVELS IN CHILDREN WITH CARIES
}

\author{
ANNISA KHAIRANI ${ }^{1}$, EVA FAUZIAH ${ }^{2 *}$, SARWORINI B. BUDIARDJO ${ }^{1}$ \\ ${ }^{1}$ Pediatric Dentistry Residency Program, Faculty of Dentistry, Universitas Indonesia. ${ }^{2}$ Department of Pediatric Dentistry, Faculty of \\ Dentistry, Universitas Indonesia. Email: eva_dens@yahoo.com
}

Received: 16 September 2017, Revised and Accepted: 3 October 2017

\begin{abstract}
Objective: Dental caries can cause pain and discomfort, especially in children. If they remain untreated, they can impact a child's oral health-related quality of life (OHRQoL) and trigger the release of salivary cortisol. Many research studies have been conducted to determine the influence of dental caries on the OHRQoL and salivary cortisol levels, but none has described the correlation between them. This research examined the correlation between the OHRQOL and the salivary cortisol levels in children with caries.
\end{abstract}

Methods: This experiment was observational and analytical with a cross-sectional design. The experimental data were statistically analyzed using the Kendall's tau and Spearman's rank correlations to compare the OHRQoL and salivary cortisol levels.

Results: The results of this study showed that there was a small correlation $(\mathrm{r}=0.3)$ between the OHRQoL and salivary cortisol level with a negative trend. This suggests that if the cortisol level slow, the child's OHRQoL is high. The chronic inflammation caused by dental caries can influence the OHRQoL and trigger the release of cortisol in the saliva.

Conclusion: Children with good OHRQoLs have low salivary cortisol levels, suggesting an unstressed condition. Practical implications: Untreated caries may cause pulpitis (represent in decayed, missing, and filled teeth in this study) in children aged 8-10 years old has an impact in their OHRQoL. Meanwhile, salivary cortisol levels as biomarker of inflammation may influence in many factors.

Keywords: Oral health-related quality of life, Salivary cortisol hormone, Caries in children.

(c) 2017 The Authors. Published by Innovare Academic Sciences Pvt Ltd. This is an open access article under the CC BY license (http://creativecommons. org/licenses/by/4. 0/) DOI: http://dx.doi.org/10.22159/ijap.2017.v9s2.31

\section{INTRODUCTION}

Children are at the highest risk for chronic tooth inflammation, which can cause pain and/or discomfort and functional limitations. Therefore, proper oral hygiene and compliance can impact a child's oral health-related quality of life (OHRQoL) [1]. The OHRQoL is an individual's perception of their health and several multidimensional functions, including their physical, emotional, psychological, social, and behavioral functions [2]. In children, the OHRQoL is different from that of adults because their cognitive maturity level differs from that of adults; therefore, specific instruments have been designed to determine a child's OHRQoL. One of these instruments that are already in use is the age group-specific (8-10 years old) child perceptions questionnaire 8-10 (CPQ8-10) [3]. If dental caries remain untreated, they can have an impact on a child's OHRQoL [4]. Moreover, the chronic inflammation caused by dental caries in children can trigger a salivary cortisol release in response to homeostasis [5].

Previous research has used the salivary cortisol to measure the blood cortisol level. In the case of pediatric patients, testing the salivary cortisol can be a better choice than using a blood sample because it is less invasive [6]. Although there have been many research studies to determine the influence of dental caries on one's quality of life [3] and on the salivary cortisol level [7], none of them has described the correlation between the OHRQoL and the salivary cortisol level. Therefore, the aim of this study was to analyze the correlation between the OHRQoL and the salivary cortisol levels in children with caries.

\section{METHODS}

The 35 subjects were 8 years old in third-grade students at the Madina Islamic Primary School in Tebet, Jakarta in Indonesia. These children had no systemic illnesses, used no medication, had no "special needs," and were not medically compromised. Any children who had eaten or exercised within $2 \mathrm{~h}$ of the data collection were excluded from this study. The parents were informed of all the study details, and their written consent was required for the child's participation.

This clinical research was carried out from October to November 2015. The study subjects were asked to answer the questions on the CPQ 8-10 form, after which they underwent a decayed, missing, and filled teeth (DMFT) index evaluation. Each saliva sample was collected using a $5 \mathrm{ml}$ tube through the passive drool technique. The data collection began at $10 \mathrm{AM}$ and ended at about $11 \mathrm{AM}$ before the children participated in any exercise activities or ate.

The analysis of the questionnaire began by scoring each question for the validation, then analyzing the Cronbach's alpha and R score using an SPSS application (SPSS Inc., Chicago, IL, USA). The salivary cortisol level was determined through ELISA testing using the 1-300 Salivary Cortisol ELISA Kit (Salimetrics, USA) and was analyzed in the Oral Biology Laboratory of the Faculty of Dentistry at the University of Indonesia in Jakarta.

\section{RESULTS}

With regard to the gender distribution, approximately $60 \%$ of the subjects were male $(n=21)$, with more than half of them reporting a good OHRQoL (quality of life, QL <3). Based on the 35 samples, the mean salivary cortisol level was $0.56 \pm 0.01 \mu \mathrm{g} / \mathrm{ml}$, with a range of $0.55-0.60 \mu \mathrm{g} / \mathrm{ml}$ (Table 1 ).

The mean DMFT score was $0.065 \pm 0.10$, with a range of $0.00-0.33$, suggesting that all of the study subjects had very low caries activity. 
Therefore, the data distribution represents a caries-free group. The salivary cortisol ranged from 0.55 to $0.60 \mu \mathrm{g} / \mathrm{ml}$, with a mean of $0.56 \pm 0.01 \mu \mathrm{g} / \mathrm{ml}$. The authors classified the salivary cortisol values into three categories: Low $(<0.56 \mu \mathrm{g} / \mathrm{ml})$, moderate $(0.56-0.57 \mu \mathrm{g} / \mathrm{ml})$, and high $(0.58-0.60 \mu \mathrm{g} / \mathrm{ml})$. More than half of the samples showed moderate salivary cortisol levels $(68.5 \%)$, followed by low cortisol levels $(22.8 \%)$ and high $(8.5 \%)$ levels (Table 2).

There was no significant correlation between the salivary cortisol level and the DMFT score, and the correlation power was weak $(r=0.14)$ (Table 3). Moreover, there was no significant correlation between the OHRQoL and the salivary cortisol level, and this correlation power was also weak $(\mathrm{r}=0.03)$.

A negative value for the correlation power would describe an inverse correlation line (Table 4).

Overall, based on the results of this study, the higher the salivary cortisol level, the lower the OHRQoL. The experimental subjects were derived from a uniform socioeconomic class to avoid bias from the many factors that can influence the results, especially the cortisol level. However, this group of children was of middle-to-high socioeconomic status, which can represent a low caries activity group.

\section{DISCUSSION}

Several studies have suggested that the oral health status is not the main factor influencing the OHRQoL. The other factors include the psychosocial status and the environment [1]. In this study, the subjects were of middle-to-high socioeconomic status, which was equivalent with the intraoral examination and a good OHRQoL. Table 1 summarizes that $80 \%$ of the total subjects had good OHRQoLs, with a mean DMFT score of 0.065 , which suggests a good oral health condition.

Many previous studies have used the salivary cortisol level as a biomarker to explore the role of maternal stress on childhood caries [8]. In addition to a response to stress or anxiety, salivary cortisol is secreted by the hypothalamic-pituitary-adrenal axis in chronic inflammation. As a consequence, inflammation of a dental origin can stimulate the excretion of salivary cortisol. This study revealed low cortisol levels in more than half of sample population, which were relevant to the DMFT scores. The correlation coefficient was 0.14 , suggesting a weak correlation with no significance ( $p>0.05$ ) (Table 2).

Table 1: Distribution of gender, quality of life, and salivary cortisol levels in the children with caries

\begin{tabular}{lll}
\hline Object & Variable & n (\%) \\
\hline Gender & Boys & $21(60)$ \\
& Girls & $14(40)$ \\
OHRQoL (CPQ8-10) & Total & $35(100)$ \\
& Low & $28(80)$ \\
Salivary cortisol & High & $7(20)$ \\
& Total & $35(100)$ \\
& Low & $8(22.8)$ \\
& Middle & $24(68.5)$ \\
& High & $3(8.5)$ \\
& Total & $35(100)$ \\
\hline
\end{tabular}

OHRQoL: Oral health-related quality of life, CPQ8-10: Child perceptions questionnaire 8-10 years old

Table 2: Mean and standard deviation values of the salivary cortisol levels and DMFT scores

\begin{tabular}{llll}
\hline Variable & n & Min-max & Mean \pm SD \\
\hline Salivary cortisol $(\mu \mathrm{g} / \mathrm{ml})$ & 35 & $0.55-0.60$ & $0.56 \pm 0.01$ \\
DMFT score & 35 & $0.00-0.33$ & $0.065 \pm 0.10$ \\
\hline DMFT: Decayed missing and filled teeth SD: Standard deviation &
\end{tabular}

The main result of this research was to determine a weak relationship between the OHRQoL and salivary cortisol level in children. Previous studies have reported that salivary cortisol is secreted in response to stress and anxiety [9]; therefore, a variation in the stress stimulus of the subject in future research may contribute to the present study.

This research population was made up of the same socioeconomic class, cognitive skills, school environment, time of intraoral examination, and data collection. This generalization was intended to avoid the different stimuli of the cortisol hormone; however, there are many more factors that could not be controlled in this study. For example, the family environment is a stress stimulus that could not be avoided but was not analyzed in this study.

The study participants had the same general and oral health status, with DMFT scores below 1.1, suggesting low caries activity. Therefore, this population of children had mild oral discomfort and/or pain. This corresponds with the good OHRQoL scores and fits with the results of previous studies. This research showed that a low caries activity level corresponds with a low salivary cortisol level.

\section{CONCLUSION}

Caries are one type of chronic dental inflammation that can trigger the secretion of cortisol in the saliva. This hormone can be used a biomarker for chronic stress in children. Moreover, chronic inflammation of a dental origin can impact many different functions, which can be measured by the OHRQoL. There was a weak correlation between the OHRQoL and salivary cortisol level; however, this research showed that these children with low caries activity had high OHRQoLs and low cortisol levels.

Table 3: Correlation between the salivary cortisol levels and DMFT scores

\begin{tabular}{lll}
\hline & \multicolumn{2}{l}{ Salivary cortisol level } \\
\cline { 2 - 3 } & $\mathbf{r}$ & $\mathbf{p}$ \\
\hline DMFT score & 0.14 & 0.42 \\
\hline DMFT: Decayed, missing, and filled teeth &
\end{tabular}

Table 4: Correlation between the OHRQoL and DMFT scores

\begin{tabular}{clllllll}
\hline & \multicolumn{2}{l}{ Cortisol } & Total & $\mathbf{r}$ & $\mathbf{p}$ \\
\cline { 2 - 4 } & Low & Middle & High & & & \\
\hline OHRQoL & & 19 & 3 & 28 & -0.33 & 0.42 \\
$\quad$ Good & 6 & 19 & 0 & 7 & & \\
$\quad$ Bad & 2 & 5 & 3 & 35 & & \\
Total & 8 & 24 & 3 &
\end{tabular}

OHRQoL: Oral health-related quality of life, DMFT: Decayed, missing, and filled teeth

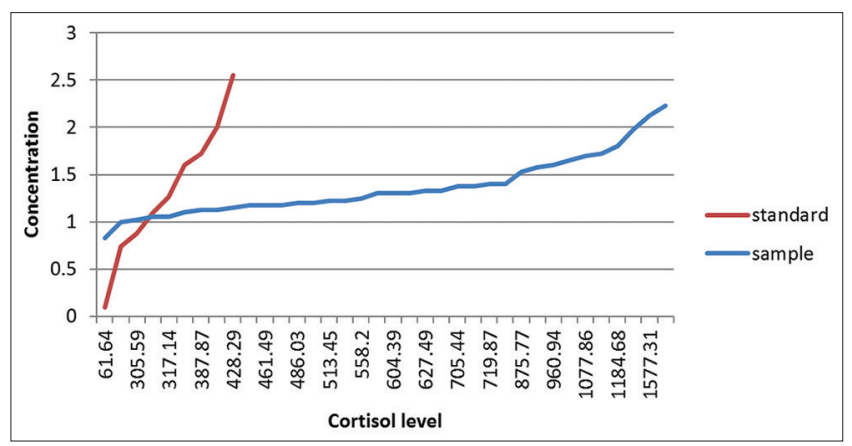

Fig 1: The cortisol levels in the samples and standard 
These results correspond to previous research that shows high caries activity correlated with a high level of salivary cortisol. This research can be used as a pilot study for future research to analyze different populations using the same trigger stimulus in stress with different caries activity levels.

\section{ACKNOWLEDGMENTS}

The publication of this manuscript is supported by Universitas Indonesia.

\section{REFERENCES}

1. Sischo L, Broder HL. Oral health-related quality of life: What, why, how, and future implications. J Dent Res 2011;90:1264-70.

2. Filstrup SL, Briskie D, da Fonseca M, Lawrence L, Wandera A, Inglehart MR, et al. Early childhood caries and quality of life: Child and parent perspectives. Pediatr Dent 2003;25:431-40.

3. Wilson IB, Cleary PD. Linking clinical variables with health-related quality of life. A conceptual model of patient outcomes. JAMA
1995;273:59-65

4. Angela A. Peran Berbagai Faktor Risiko Karies Terhadap Kejadian Karies pada Anak Usia 4-5 Tahun. ???: Universitas Indonesia; 2008

5. Tordjman S, Anderson GM, Kermarrec S, Bonnot $\mathrm{O}$, Geoffray MM, Brailly-Tabard S, et al. Altered circadian patterns of salivary cortisol in low-functioning children and adolescents with autism. Psychoneuroendocrinology 2014;50:227-45.

6. Putnam SK, Lopata C, Fox JD, Thomeer ML, Rodgers JD, Volker MA, et al. Comparison of saliva collection methods in children with highfunctioning autism spectrum disorders: Acceptability and recovery of cortisol. Child Psychiatry Hum Dev 2012;43:560-73.

7. Pani SC, Al Odhaib M. The impact of dental treatment on the salivary cortisol levels of children with severe early childhood caries. Eur Arch Paediatr Dent 2013;14:307-12.

8. Pani SC, Abuthuraya D, Alshammery HM, Alshammery D, Alshehri H. Salivary cortisol as a biomarker to explore the role of maternal stress in early childhood caries. Int J Dent 2013;2013:565102.

9. Barbosa TS, Castelo PM, Leme MS, Gavião MB. Associations between oral health-related quality of life and emotional statuses in children and preadolescents. Oral Dis 2012;18:639-47. 